\title{
Roland Barthes diante do signo fotográfico
}

\author{
Leda Tenório da Motta \\ Professora do Programa de Pós-Graduação em Comunicação e Semiótica da PUC/SP. Crítica \\ literária e tradutora. Publicou, entre outros, Proust: a violência sutil do riso (Perspectiva, \\ 2007), obra vencedora do Prêmio Jabuti 2008, na categoria Teoria/Crítica literária. \\ E-mai:ltmotta@pucsp.br \\ Rodrigo Fontanari \\ Doutorando do Programa de Pós-Graduação em Comunicação e Semiótica da PUC/SP. \\ Pesquisador bolsista da Fundação de Amparo à Pesquisa do Estado de São Paulo, com Estágio \\ de Pesquisa no Centre Roland Barthes da Université de Paris VII - Denis Diderot. \\ E-mail: rodrigo-fontanari@hotmail.com
}

Resumo: Em A câmara clara, Roland Barthes elabora uma reflexão decisiva sobre a fotografia. Nessa obra, o semioticista que denuncia os mitos da fotografia passa a poeta das imagens pungentes, em um convite à difícil tarefa de reconhecer as riquezas singulares que podem vir a ser eternizadas em uma imagem fotográfica. Temos aí outro olhar em direção a imagens técnicas, bem diverso daquele vindo da tradição bem-pensante, com seu veto aos simulacros. Nesse sentido, jogamos com a hipótese de que as teses de $A$ câmara clara ganhariam se fossem entendidas como um pensamento sui generis sobre o signo fotográfico.

Palavras-chave: Roland Barthes, fotografia, punctum, studium, estética.
Abstract: In The camera lucida, Roland Barthes forms a critical reflection on photography. In this work, the semiotician denouncing the myths of the photograph is the poet of haunting images to an invitation to the difficult task of recognizing the natural riches that may be perpetuated in a photographic image. I fear there another look toward the imaging techniques, and other than that coming from the well-thinking tradition, with his veto of the simulacra. We played with the hypothesis that the theses of the camera clearly benefit from being perceived as a sui generis thinking about the photographic sign.

Keywords: Roland Barthes, photography, puctum, studium, aesthitics.

\section{INVESTIGANDO A SEMIÓTICA}

A derradeira obra em vida de Roland Barthes - crítico e semiólogo, um dos mais importantes pensadores franceses do século XIX - A câmara clara, de 1980, poderia ser lida como um "poema" ou mesmo uma "forma poética do luto", entendendo por isto simplesmente algo que seja memorável (memorabilis), ou seja, digno de ser mantido na memória. Com o subtítulo "Nota sobre fotografia - porque é um livro breve que não tem nenhuma pretensão enciclopédi$\mathrm{ca}^{\prime 1}$-, acena que, em suas páginas, o leitor encontrará uma teoria (lembrando que, em grego, theoría significa visão) sobre a fotografia elaborada por Barthes para pensar e ler esse tipo de imagem técnica. Já nas primeiras linhas do texto, deparamo-nos com uma abertura que lembra um romance - ou melhor, o

1. BARTHES, Roland. Du goût à l'extase. Oeuvres Complètes [Do êxtase ao gosto. Obras completas]. Paris: Seuil, 2002. p. 930. 
comunicação \& educação • Ano XVII • número 1 • jan/jun 2012

2. Ibid., p. 791.

3. Ibid., p. 841

4. PERRONE-MOISÉS Leyla. La langage de Roland Barthes [A linguagem de Roland Barthes]. In La Quinzaine Littéraire n. 191. Paris: Juillet, 1974

5. Ibid., p. 23

6. O termo óbvio, etimologicamente "aquilo que vem à frente", refere-se ao que é naturalmente apresentado, ao sentido construído pela representação. Obtuso é o "demais", aquilo que "minha intelecção não consegue absorver bem, simultane amente teimoso e fugidio [...]". BARTHES, Roland. Le troisième sens. Oeuvres Complètes, III [O terceiro sentido. Obras completas, III]. Paris: Seuil, 2002. p. 489-492.

7. O studium é um cam po de estudo "que não quer dizer, pelo menos de imediato, 'estudo', mas a aplicação a uma coisa, o gosto por al guém. Uma espécie de investimento geral ardoroso, é verdade, mas sem acuidade particular...". Já o punctum é o lugar das sentimentalidades, um ponto cortado no tempo e no espaço onde está depositado todo um momento de emoção. Nas palavras de Barthes, "o punctum de uma foto é esse acaso que, nela me punge (mas também me mortifica, me fere)". BARTHES, Roland. La chambre claire. Oeuvres Complètes, V [A câmara clara. Obras completas, V] Paris: Seuil, 2002. p. 899/809.

8. NÖRTH, Winfried. A semiótica no século $X X$. São Paulo: Annablume, 2001 livro apresenta uma dupla abertura romanesca, visto que se encerra em dois momentos compostos de vinte e quatros fragmentos cada. A primeira parte se abre com: "Um dia, há muito tempo, dei com uma fotografia do último irmão de Napoleão, Jerôme"². A segunda: "Ora, numa noite de novembro, pouco depois da morte de minha mãe, organizei as fotos" ${ }^{3}$. Para além de um texto teórico, A câmara clara é um mergulho no mundo poético do olhar. Entre seus fragmentos, percebemos que, "quando se pensa ter discernido uma linha, ela se rompe; quando se acredita ter amadurecido conceitos ou métodos, somente reencontra entre as mãos belos objetos inúteis, sem função desde que eles são retirados de seus próprios sistemas".

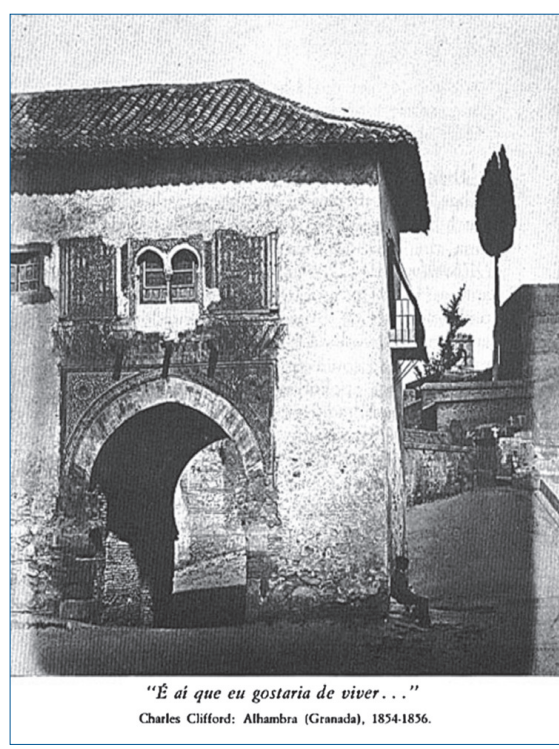

Imagem contida no livro A câmara clara, de Barthes.
A câmara clara não é um labirinto poético que rompe com qualquer tentativa de compreensão do texto, como uma teoria semiótica da fotografia ou, ainda, do retrato fotográfico. Talvez Leyla Perrone-Moisés tenha razão mais uma vez quando, em La Langage de Roland Barthes, nota que:

Nada mais deprimente que ver os textos de Barthes considerados como objetos intelectuais, de encontrá-los resumidos, analisados e discutidos do ponto de vista de sua cientificidade, de seu valor heurístico, de seu aporte metodológico de seu engajamento político. De ver este pensamento interrogado um pensamento, esta voz interpelada com aquela de um sujeito, este rigor tomado por um professor, este escritor lido como se de um escritor se tratasse ${ }^{5}$.

Ao ler as obras completas, podemos recortar daí uma sutil teoria da fotografia, ou melhor, uma maneira de ler esse tipo de imagem técnica a partir do par opositivo óbvio/obtuso ${ }^{6}$ desenvolvido em seu artigo sob os fotogramas de Eisenstein, O terceiro sentido: notas de pesquisa sobre alguns fotogramas de S. M. Eisenstein - ou mesmo os conceitos já clássicos de studium/punctum ${ }^{7}$ estabelecidos em A câmara clara. Porém, isso tudo não parece sustentar escopo teórico suficiente para a afirmação assertiva de que exista uma "semiótica" ou uma "semiologia" da fotografia no sentido stricto sensu dos dicionários de semiótica. Em A semiótica no século XX, Winfried Nöth sublinha que os termos "semiótica", "semiologia" e "estruturalismo" são tomados quase como sinônimos ${ }^{8}$. Verifiquemos as definições estabelecidas por Algirdas, Julien Greimas e Joseph Cortés em Sémiotique: dictionnaire raisonné de la théorie du langage para o verbete "semiologia":

O projeto semiótico, na medida em que se procura desenvolvê-lo no quadro restrito da definição saussuriana (e fora de todo contato com a epistemologia das ciências humanas da época) - O "sistema" excluindo o processo semiótico 
e, não obstante, as práticas significantes as mais diversas; o estudo dos "signos", inscrito na teoria da comunicação, consistindo na aplicação quase mecânica do modelo de "signo linguístico".

E para "semiótica":

Emprega-se em sentidos diferentes, segundo que se designa uma grandeza qualquer manifestada, que se propõe a conhecer; um objeto de conhecimento, tal que aparece no curso e em seguida sua descrição e o conjunto de meios que tornam possível seu conhecimento ${ }^{10}$.

O termo semiótica (em grego sêmeiôtikê) advém de sêmion, "signo". Em sentido filosófico e lógico, a semiótica se expressa como uma teoria geral dos signos e suas articulações no pensamento. Pelo viés semiológico, a palavra assume o sentido de uma teoria dos signos ou dos sentidos e de suas articulações na sociedade.

Oswald Ducrot e Jean-Marie Schaeffer, em Nouveau Dictionnaire Encyclipédique des sciences du langage, sublinham que o termo semiótica ou semiologia é o estudo dos signos e dos processos interpretativos. Destacam ainda que a reflexão a respeito dos signos não nasceu recentemente, remontando à antiguidade grega. É das mãos do filósofo John Locke que surgiria definitivamente o nome "semiótica", entendido como "conhecimento dos signos" - o signo como relação de referência a um acontecimento percebido ${ }^{11}$.

De maneira mais ampla, entendemos a semiótica como um pensamento sobre a linguagem, uma ciência que estuda todos os fenômenos culturais como se fossem sistemas de signos - tomando como base a hipótese de que todos os fenômenos de cultura são sistemas de signos. Em outras palavras, a cultura é essencialmente comunicação e a semiologia, ou semiótica, seria então "a ciência que estuda a vida dos signos no seio da vida social"12.

Por outro lado, como pesquisadores de Barthes, não podemos negar todo o seu empenho em construir, em meados dos anos 1960, uma semiologia ou semiótica. Várias de suas obras marcam seu percurso e mergulho nessa "ciência dos signos na vida social" - a começar pelo importante manual de resenha de termos técnicos de linguística, Elementos de semiologia, seguido da extensa pesquisa semiológica Sistema da moda, que podemos considerar a obra mais próxima da semiótica hjelmesviana - ou da análise da narrativa realizada em $S / Z$, entre outras incursões desse intelectual francês no campo stricto da semiologia francesa em um período considerado estruturalista.

\section{A SEMIÓTICA E O "NEUTRO"}

Sabemos que, pouco a pouco, nos anos de 1970, Barthes se afastou desse universo de termos técnicos para alçar novos voos epistemológicos, já que para ele as pesquisas científicas haviam se tornado um conjunto de trabalhos indiferentes e indiferenciáveis em relação ao seu corpus. Essa indiferença científica foi bem sublinhada por ele na obra Roland Barthes por Roland Barthes, e, mais

9. GREIMAS, A. J.; CORTÉS, J. Sémiotique: dictionnaire raisonné de la théorie du langage [Semiótica: dicionário da teoria da linguagem]. Paris: Hachette, 1993. p. 336.

10. Ibid., p. 339.

11. DUCROT, Oswald; SCHAEFFER, Jean-Marie. Nouveau dictionnaire encyclopédique des sciences du langage [Novo dicionário enciclopédico das ciências da linguagem]. Paris: Seuil, 1995. p. 214.

12. SAUSSURE, Ferdinand. Cours de linguistique générale [Curso de linguística geral]. Paris: Payot, 1972. p. 33. 
comunicação \& educação • Ano XVII • número 1 • jan/jun 2012

13. BARTHES, Roland. Roland Barthes par Roland Barthes. Oeurres Com plèts [Roland Barthes por Roland Barthes. Obras Completas]. Paris: Seuil, 2002. p. 735 .

14. Cabe, aqui, uma explicação a respeito do uso das palavras "escrita" e "escritura" em Roland Barthes. A escrita se diferencia da escritura por ter valor por si mesma, sendo intransitiva, cuja importância está na prática semiótica e em um trabalho com e de palavras - enquanto a escrita não teria valor senão por seu conteúdo. A escrita transitiva é aquela em que a expressão está no falar sobre alguma coisa, ou alguém, em seu con teúdo. BARTHES, Roland. Écrivains, intellectuels, professeurs. Oeuvres Complèts [Escritores, intelectuais, professores. Obras Completas]. Paris: Seuil, 2002; BARTHES Roland. La preparation du roman [A preparação do romance]. Paris: Seuil-IMEC, 2004.

16. PERRONE-MOISÉS Leyla. Op. cit., p. 23.

17. Cf. BARTHES, Roland. Roland Barthes par Roland Barthes, cit., p. 735

16. BARTHES, Roland. Lecon. Oeuvres Complètes [Lição. Obras completas]. Paris: Seuil, 2002. p. 432.

18. Ibid., p. 441

19. Roland Barthes apresenta, em Aula, uma noção particular de literatura, uma instância possivel para trapacear a língua e trapacear com a língua: "Esta trapaça salutar, essa esquiva, esse ogro magnífico que permite ouvir a língua fora do poder, no esplendor de uma revolução permanente da linguagem, eu a chamo, quanto a mim: literatura". Leçon, cit., p. 433. especificamente, no fragmento "A ciência dramatizada": "sob [...] condição que se diga no corpus o corpo [...], se pesquise não somente a estrutura, mas a figura da enunciação: quer que se tenha com esse conjunto qualquer relação amorosa (na falta de corpus não é mais do que um imaginário científico)"13.

O deslocamento barthesiano no sentido de reivindicar o corpo na ciência demonstra que ele não tinha a pretensão de ser um teórico do signo, uma projeção da sombra da ciência do signo (semiologia) ou mesmo um cabedal científico sobre o qual seus seguidores pudessem hospedar seus diversos temas e objetos de pesquisa. No entanto, ele foi realmente fiel a um único princípio: o prazer da escrita ("escritura") ${ }^{14}$, que impulsionou Leyla Perrone-Moisés a dizer: "É a escritura que queima as cartas e diante dela que os linguistas recuam"15.

Desse semiólogo que reivindica o gozo da escritura, não restou mais que o sujeito político, que viu ("eu vejo a linguagem") ${ }^{16}$ na língua uma instância de poder que o fez dizer, em seu Aula, texto inaugural para a disciplina de Semiologia Literária no Collège de France, que "A língua [...] é simplesmente fascista, pois o fascismo não impede de dizer, é obrigar a dizer"17.

Nesse sentido, o trabalho semiológico de Roland Barthes se norteou pela tentativa de combater essa "diabrura" que é o signo linguístico. O combate só o fez desejar encarar o signo sob sua forma mais utópica: o vazio. Nas palavras do próprio Barthes, "Alguém que se debateu, toda sua vida, para o melhor e o pior, esta diabrura, a linguagem, só pode ser fascinado pelas formas de seu vazio que o contrário absoluto de seu oco"18.

Esse trabalho com o signo (literatura) ${ }^{19}$ e contra o signo (isenção de sentido ${ }^{20}$, que Barthes constrói, subverte o conceito saussuriano de signo: o laço entre o significante (imagem acústica) e o significado (conceito) ${ }^{21}$. Ao desejar uma forma "vazia", ele busca anular o significado em detrimento de um significante puro. "Visivelmente, ele sonha com um mundo que fosse isento de

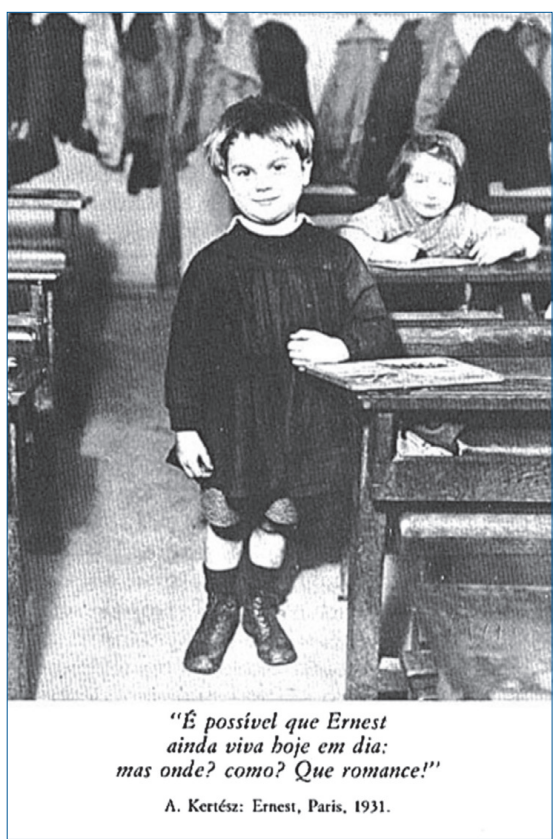

Imagem contida no livro A câmara clara, de Barthes. sentido (como de um serviço militar).

Isso começou com o grau zero, onde se sonha a ausência de qualquer signo; em seguida, mil afirmações desse sonho (acerca do texto de vanguarda, do Japão, da música, do alexandrino etc.)"22.

Essa concepção de signo desejada por Roland Barthes parece não ser aceitável para um linguista saussuriano, tal como seria impossível para um hjelmesviano pensá-lo como signo de alguma coisa ou como a expressão de um conteúdo. 
Barthes estava "sonhando alto" - expressão do próprio autor no Collège France - com uma ideia de signo que vai ao encontro, por sua vez, de seu conceito de "neutro", entendido como toda inflexão que esquive a estrutura paradigmática do sentido visando à suspensão dos dados conflituosos do discurso.

Figuras do Neutro: a escrita branca, isenta de todo teatro literário - a linguagem adâmica - a insignificância deleitável - o liso - o vazio, o inconsútil [...] a ausência de imago - a suspensão de julgamento, de processo [...] o gozo: toda esquiva, desmonta ou torna irrisórios a exibição, o domínio, a intimidação ${ }^{23}$.

Esse "segundo Barthes" já não parece mais voltar seu olhar para as redes de articulações das formas. Antes, procura perscrutar o signo $e$ até mesmo classificá-lo, a exemplo do que fizera em A câmara clara. Ao se colocar como selvagem diante da imagem fotográfica, Barthes observa o signo fotográfico como emanação do referente: "[...] A fotografia traz sempre consigo seu referente [...] eles são colados um ao outro, membro por membro como o condenado acorrentado a um cadáver em certos suplícios" ${ }^{24}$. Portanto, trata-se de uma imagem indiciária na concepção peirceana do termo, mantendo com o objeto uma conexão existencial. Para que a imagem fotografada de um sujeito possa estar sob a chapa metálica da fotografia, é necessário que haja uma conexão de fato entre o sujeito fotografado e os sais de prata. No entanto, o registro fotográfico não é a pessoa. Ele apenas a indica segundo certos limites próprios da fotografia. A fotografia é um corte específico no tempo e no espaço. A imagem que se pôs sob a superfície da chapa metálica age como um ícone do sujeito, porque ela é resultado de uma conexão, de fato, entre a tomada da foto e o sujeito (foi necessário o sujeito existir e ter estado diante da objetiva para que a imagem fotográfica se revelasse $)^{25}$. Nesse sentido, Roland Barthes coloca em cena o "referente", o que seria inaceitável para uma semiótica ou semiologia de ancoragem na linguística saussuriana. Nela, a exclusão do referente é uma condição necessária. Barthes, na condição de "sujeito impuro" ${ }^{26}$, tal como se define em Aula, embaralha e desloca conceitos da semiótica francesa, originada da linguística estruturalista saussuriana, de um lado, e da semiótica de origem americana, estabelecida por Charles Sander Peirce, de outro. Essa distinção dificulta acomodar confortavelmente o termo "semiótica" nos escritos barthesianos após 1970 (se não na acepção larga de uma teoria geral dos modos de significar ou de significação), sobretudo em A câmara clara - em que a linguagem poética eclipsa qualquer tentativa de fazer "revelar" um modelo semiótico de leitura para as imagens fotográficas, a não ser por uma sutil inscrição sugerida pelo opositivo Studium/Punctum. Os quarenta e oito fulgurantes fragmentos desse livro configuram um pensar estético do signo fotográfico com breves pinceladas de um olhar semiótico ou semiólogico capaz de observar a natureza a partir dessa representação técnica. Trata-se de um pensar estético na concepção do termo grego vindo de um verbo traduzido por sentir, ou seja, uma ciência que considera o "bonito" com uma percepção confusa ou um sentimento. Numa compreensão mais livre, seria a estética como aquilo que passa pelo corpo e provoca fruição (gozo). Talvez devêssemos tomar esse livro a partir de uma perspectiva filosófica e estética da fotografia.
20. Essa noção de isenção de sentido estaria próxima do vazio que, de uma maneira mais clara, poderia ser exemplificada pelo ato de escutar uma língua cujo sentido não compreendemos. Para nós, esses sons seriam pura substância, para falarmos em termos hjelmeslevianos, ou então a "pura significância, infinita sem profundidade". COMMENT, Bernard. Roland Barthes vers le Neutre [Roland Barthes em direção ao neutro]. Paris: Christian Bourgois Éditeur, 2002. p. 75.

21. Cf. SAUSSURE, Ferdinand. Cours de linguistique générale [Curso de linguística geral]. Paris: Payot, 1972.

22. BARTHES, Roland. Roland Barthes par Roland Barthes, cit., p. 664.

23. Ibid., p. 707.

24. BARTHES, Roland. La chambre claire, cit., p. 793.

25. Cf. DUBOIS, Philippe. L'acte photographique [O ato fotográfico]. Paris: Nathan, 1990. Cf. SANTAELLA， Lucia; WINFRIED, Nöth. Imagem: cognição, semiótica e mídia. São Paulo: Iluminuras, 2005.

26. BARTHES, Roland. Leçon, cit., p. 429. 


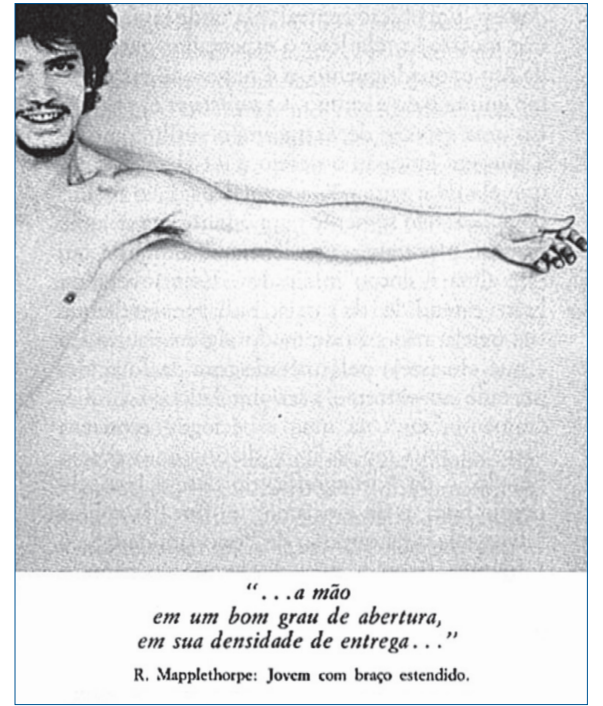

Imagem contida no livro A câmara clara, de Barthes.
O próprio Barthes nos autoriza a ler A câmara clara a partir de um viés diverso, sem a pretensão de traçar uma teoria semiótica da fotografia. Quando, por ocasião da publicação do livro, Barthes foi chamado a uma entrevista, em que ressaltou: "[...] Não é nem uma sociologia, nem uma estética, nem uma história da foto. É, sobretudo, uma fenomenologia da fotografia" ${ }^{27}$. Porém, embora nesse pequeno trecho recolhido da entrevista o autor negue a possibilidade de uma estética da fotografia, a leitura do conjunto das Oeuvres Complètes nos impele a visualizar um projeto em torno de uma ideia de signo que extrapole o campo linguístico e semiótico, o qual parece estar mais próximo da idealização estética do vazio dos signos - que no campo fotográfico se denominaria sob o conceito de punctum ou de obtuso, utilizando ainda nomenclaturas barthesianas.

\section{CONSIDERAÇÕES FINAIS}

Se, após 1970, a escritura barthesiana não comporta a arrogância do discurso científico, é porque desliza para "o discurso estético", sintoma que o próprio autor traz a público em Roland Barthes por Roland Barthes.

Ele tenta desenvolver um discurso que não se enuncie em nome da Lei e/ou da Violência: cuja instância não seja nem política, nem religiosa, nem científica; que seja, de certa forma, o resto e o suplemento de todos esses enunciados.

Como chamaríamos esse discurso? Erótico, sem dúvida, pois ele tem a ver com o gozo; ou talvez ainda: estético, se previrmos submeter pouco a pouco essa velha categoria a uma ligeira distorção, que a afastará de seu fundo regressivo, idealista, e a aproximará do corpo da deriva ${ }^{28}$.

A câmara clara, que poderíamos considerar a última incursão barthesiana na fotografia, é um trabalho de escritura que traz, já em suas primeiras linhas, um belíssimo questionamento: saber, a qualquer custo, o que seria essa imagem "em si mesma". Trata-se de um trabalho de pesquisa sobre o signo fotográfico muito próximo da estética da imagem fotográfica - e que a diferencia dos outros tipos de imagens. Pelas mãos de Roland Barthes, temos:

Eu estava tomado por um olhar da fotografia, de um desejo "ontológico": eu queria a todo preço saber o que ela era "em si mesma", por que traço essencial ela se distinguia da comunidade das imagens. Um desejo como esse queria dizer que, no fundo, fora das evidências provenientes da técnica e do uso ${ }^{29}$. 
Essa estética do vazio está ainda em vias de ser elaborada. Porém, parece cada vez mais evidente que todo projeto de escritura barthesiana, desde $O$ grau zero da escrita até Preparação do romance, passando por Neutro, faz-se pela busca da forma vazia. Notadamente, Phillipe Forest, em Le temps retrouvé de Roland Barthes, publicado na revista Arc, sublinha a necessidade de "[...] traçar a genealogia, interrogar os limites - faz ressaltar a problemática do sentido e da sua suspensão" ${ }^{30}$.

Basta, por ora, sinalizar a possibilidade de desenvolver a concepção de signo e de suas bases epistemológicas, o que seria uma enorme contribuição para as artes em geral. Com isso, acreditamos que o título dessa obra barthesiana poderia ter sido A câmara clara - Nota para uma estética do signo fotográfico.

\section{REFERÊNCIAS BIBLIOGRÁFICAS}

BARTHES, Roland. Oeuvres Complètes [Obras Completas]. Paris: Seuil, 2002.

COMMENT, Bernard. Roland Barthes vers le Neutre [Roland Barthes em direção ao neutro]. Paris: Christian Bourgois Éditeur, 2002. p. 75.

DUBOIS, Philippe. L'acte photographique [O ato fotográfico]. Paris: Nathan, 1990.

FOREST, Phillipe. Le temps retrouvé de Roland Barthes [O tempo ganho de Roland Barthes]. In: Arc, Paris, 1996.

GREIMAS, Algirdes Julien; CORTÉS, Joseph. Sémiotique: dictionnaire raisonné de la théorie du langage [Semiótica: dicionário da teoria da linguagem]. Paris: Hachette, 1993.

PERRONE-MOISÉS, Leyla. La langage de Roland Barthes [A linguagem de Roland Barthes]. In: La Quinzaine Littéraire, n. 191, Paris: Juillet, 1974.

SANTAELLA, Lucia; WINFRIED, Nöth. Imagem: cognição, semiótica e mídia. São Paulo: Iluminuras, 2005.

SAUSSURE, Ferdinand. Cours de linguistique générale [Curso de linguística geral]. Paris: Payot, 1972.

NÖTH, Winfried. A semiótica no século XX. São Paulo: Annablume, 2001.

30. FOREST, Phillipe. Le temps retrouvé de Roland Barthes [O tempo ganho de Roland Barthes]. In: Arc, p. 60, Paris, 1996. 